\title{
A REPRESENTAÇÃO DO GÊNERO EM MARISA: O QUE FAZER COM ESSES NÚMEROS?
}

Alisson Machado, Carline Ternus, Gabriela Silva dos Santos 
A REPRESENTAÇÃO DO GÊNERO EM MARISA: O QUE FAZER COM ESSES NÚMEROS?

Resumo: Este artigo problematiza a relação publicidade/gênero, tendo como objeto um produto audiovisual publicitário das lojas Marisa. Utilizamos como aporte teórico os Estudos Culturais britânicos, com ênfase no Circuito da Cultura, proposto por Paul Du Gay et al. (1997). A regulação do produto ocorreu por parte dos consumidores, que se utilizaram da internet como ferramenta interativa, para manifestarem suas opiniões.

Palavras chave: Publicidade; Gênero; Circuito da cultura; Estudos Culturais

\section{LA REPRESENTACIÓN DE GÉNERO EN MARISA: QUE HACER CON ESTOS NUMEROS?}

Resumen: En este artículo se analiza la relación entre publicidad/género, concentrándose en un objeto audiovisual de publicidad de las tiendas Marisa. Utilizado como referencia los teóricos de los estudios culturales británicos, con énfasis en el Circuito de la Cultura, propuesto por Paul Du Gay et al. (1997). La regulación del producto fue producida a partir de los consumidores que han utilizado el internet como herramienta interactiva para expresar sus opiniones. Palabras clave: Publicidad; Género; Circuito de la cultura, Estudios Culturales

GENDER REPRESENTATION IN MARISA: WHAT TO DO WITH THESE NUMBERS?

Abstract: This article discusses the relationship between advertising and gender, having as object an audiovisual advertising from Marisa department store. We use the British Cultural Studies as theoretical framework, with emphasis on the Circuit of Culture, proposed by Paul Du Gay et al. (1997). The regulation of the product has occurred on the part of consumers, who used the internet as an interactive tool to express their opinions.

Keywords: Advertising; Gender; Circuit of Culture; Cultural Studies 


\section{INTRODUÇÃO}

A publicidade está presente no nosso dia a dia, nos interpelando em todos os meios de comunicação: quando estamos assistindo televisão, ouvindo rádio, lendo revista, jornal, "navegando" na internet e até mesmo nas ruas.

Há tempos a publicidade não é mais um mero aporte do capitalismo, mantendo intenções estritamente mercadológicas. Ela é, também, muitas vezes, um produto cultural, construída através do uso de estereótipos de representações, inscritos em valores, hábitos e práticas culturais. É claro que não podemos dizer que a publicidade, por si só, aliena e/ou impõe valores. Nesse sentido, Melo (1991) citado por Jacks; Piedras (2005) afirma que

a publicidade reflete os valores existentes e respalda o ponto de vista dominante, [mas ela] não pode ser tomada como responsável única pelas opiniões, normas e valores dominantes, nem tampouco ser absolvida de toda a responsabilidade por elas (MELO, 1991 apud JACKS; PIEDRAS, 2005, p. 199).

A responsabilidade pelas representações é de todo o sistema capitalista, do qual a publicidade consiste apenas em uma parte. Para as mulheres, por exemplo, a publicidade reafirma o padrão de beleza que já está naturalizado na sociedade. É sabido que esse padrão muda conforme a época, mas, na atualidade, podemos dizer que ele afirma que a mulher deve ser magra, sensual, vestir-se bem, ser confiante, e mais ainda, ela precisa direcionar suas atividades - e seu ser - ao homem, motivo de sua felicidade.

Se a publicidade começasse a relativizar os estereótipos existentes, os padrões impostos, que por vezes incomodam e indignam alguns grupos, por serem excludentes, já seria um passo a frente na busca por uma sociedade com menos preconceitos, menos desigual. A “culpa” em si não é da publicidade, mas de todo um sistema de representações sociais - no qual a publicidade se inclui - que constroem e reafirmam posições muitas vezes desiguais e hierárquicas entre os indivíduos.

Para demonstrar/reafirmar que o debate sobre as relações de gênero ainda não cessou, escolhemos como objeto de pesquisa deste artigo um comercial intitulado "Números", da rede de lojas de departamento Marisa, que se utilizou de estereótipos na construção de sua narrativa. Para trabalharmos com este produto audiovisual optamos por utilizar o Circuito da Cultura, de Du Gay 
et al. (1997), como instrumento analítico advindo do campo dos Estudos Culturais, onde todas as instâncias do produto midiático (produção, representação, identidade, consumo e regulação) são destacadas.

O artigo está dividido em: 1) um breve histórico sobre os Estudos Culturais e suas contribuições; 2) questões acerca do debate entre gênero e publicidade, onde traçamos um breve histórico do papel feminino que foi construído ao longo dos anos e encaminhamos uma reflexão sobre publicidade e gênero; e 3) a inserção da peça publicitária, o produto audiovisual das Lojas Marisa, nas instâncias do Circuito da Cultura proposto por Du Gay, no qual buscamos perceber de que formas as diferentes instâncias que compõem este modelo relacionam-se entre si, tendo em vista a circulação da referida publicidade.

\section{UMA INTRODUÇÃO AOS ESTUDOS CULTURAIS}

O Centro Contemporâneo de Estudos Culturais (Centre for Contemporary Cultural Studies) foi fundado em 1964, por Richard Hoggart. O Centro surge ligado ao departamento de Inglês (Literatura) da Universidade de Birmingham, na Inglaterra e constitui-se em um núcleo de pós-graduação. Tem como objetivo o estudo das relações entre: (1) cultura contemporânea e sociedade, suas formas culturais, instituições, práticas culturais e (2) sociedade e mudanças sociais. Há três textos que surgiram na década de 1950 e que são identificados como a fonte dos Estudos Culturais. São eles: The Uses of Literacy, de Richard Hoggart, que, além de ser autobiográfico, retrata a história cultural da metade do século XX; Culture and Society, de Raymond Williams, no qual o autor constrói um conceito de cultura, disseminando a ideia de que a cultura "comum ou ordinária" pode ser vista como um modo de vida; e The Making of the English Working-class, de E.P Thompson, que reconstrói uma parte da história da sociedade inglesa sob seu ponto de vista (ESCOSTEGUY, 2001).

Na pesquisa de Hoggart, o foco são os materiais culturais da cultura popular e dos meios de comunicação de massa, que antes não eram abordados por meio da metodologia qualitativa. Inaugura-se neste trabalho o conceito de que o popular não existe apenas na submissão, mas, também, na resistência, o que posteriormente seria usado pelos estudos de audiência dos meios massivos. Para Williams e Thompson, de acordo com Escosteguy (2001, p. 1), "cultura era uma rede vivida de práticas e relações que constituíam a vida cotidiana, dentro da qual o papel do indivíduo estava em primeiro plano". 
Apesar de Stuart Hall não ter feito parte da fundação do Centro Contemporâneo de Estudos Culturais, sua importância é inegável, pois, ao substituir Hoggart na direção do Centro, incentivou a investigação de práticas de resistência de subculturas e análises dos meios massivos.

Os estudos do Centro englobam ainda a ideologia, visto que a cultura tem a influência direta desta. De acordo com Williams (2007, p. 215), no último século, a ideologia é considerada como um "conjunto de ideias que surgem de um dado conjunto de interesses materiais ou, em termos mais gerais, de uma classe ou grupo definido" (WILLIAMS, 2007).

Rompendo com um passado, que identificava a cultura apenas com artefatos, os pioneiros dos Estudos Culturais, sobretudo nos trabalhos de Raymond Williams, articulam um conceito expandido de cultura, que inclui as formas pelas quais os rituais da vida cotidiana, instituições e práticas, juntamente com as artes, são constitutivos de uma formação cultural. Nesse momento, em que os Estudos Culturais passam a considerar as formas de expressão culturais não-tradicionais, de acordo com Escosteguy (2001, p. 1), "se descentra a noção de cultura e a cultura popular ganha legitimidade, transformando-se num lugar de atividade, crítica e intervenção". Os Estudos Culturais passaram, então, a questionar o estabelecimento de hierarquias entre formas e práticas culturais, como as binariedades de cultura alta/baixa, superior/inferior, entre outras.

Paul Du Gay, Stuart Hall, Linda Janes, Hugh Mackay e Keith Negus, todos ligados aos Estudos Culturais, compartilham a ideia de que a cultura ocupa hoje um espaço muito importante na sociedade, como um processo que constitui práticas econômicas e políticas. A cultura gera significados e é por isso que:

A produção de sentidos sociais é, portanto, uma condição necessária para o funcionamento de todas as práticas sociais e um relato das condições culturais das práticas sociais deve fazer parte da explicação sociológica de como estas práticas funcionam. A descrição e a análise cultural são, portanto, cruciais para a produção de conhecimento sociológico (DU GAY, et al., 1997, p. 2).

Portanto, através da análise de produtos culturais pode-se entender as práticas sociais de determinada sociedade e, conseqüentemente, sua constituição. Por isso, Du Gay, et al. (1997) criaram um instrumento analítico denominado "circuito da cultura". Este circuito compreende cinco etapas, articuladas entre si. Escosteguy (2009, p. 4) afirma que "esse protocolo integra os espaços 
da produção e da recepção/consumo, enfraquecendo a premissa de 'autonomia relativa' entre eles".

As cinco etapas que compõem o circuito são: representação, identidade, produção, consumo e regulação. Neste circuito, nenhum momento é privilegiado. É por meio da combinação de todos os momentos, neste artigo, que o produto cultural é atribuído de sentido/significado.

A produção, além do sentido convencional dos procedimentos necessários para criação de um artefato/produto, abarca também "as distintas narrativas que se associam à invenção desses mesmos produtos" (ESCOSTEGUY, 2009, p. 9), isto é, os discursos. Já o consumo refere-se ao que as pessoas vão fazer com tais artefatos/produtos. São os atores em ação. Por isso, produção e consumo não constituem esferas separadas, elas se completam.

A representação "é entendida como a associação de significações a um determinado artefato/produto, desse modo, o sentido não surge do 'próprio objeto', mas da forma como ele é representado pelas linguagens" (ESCOSTEGUY, 2009, p. 10). Assim, durante o consumo os receptores vão formando seus significados e expondo-os através da linguagem/discurso.

Nossas identidades são processos constantemente em construção, que se dá a partir da linguagem e das representações. Sua presença no circuito da cultura ocorre porque a "moldamos" de acordo com os usos sociais que delas fazemos, a partir das representações que criamos das mensagens.

A regulação entra no processo como um tensionamento das relações entre cultura e poder. Todos os meios possuem regulação, no caso do anúncio estudado neste artigo, temos a regulação televisiva, a regulação publicitária (o CONAR) e ainda a regulação da audiência, que pode expor suas opiniões sobre o que achou do produto midiático, ela pode concordar com o anúncio, discordar ou mesmo denunciá-lo como impróprio.

Todos os produtos culturais realizam as cinco etapas do circuito para se introduzirem na sociedade. Por isso, utilizaremos este instrumento analítico na análise de um comercial televisivo, que constitui um produto cultural.

\section{QUESTÕES DE GÊNERO E DE PUBLICIDADE}

As questões relacionadas ao debate de gênero, que teorizam a diferença sexual entre homens e mulheres, ao mesmo tempo em que questionam os papeis sociais destinados a cada um deles, estão intimamente ligadas ao corpo, 
principalmente, aos usos sociais dos corpos. É no corpo que se inscrevem as marcas do gênero. Como aponta Sandra Regina Goulart Almeida (2002), o gênero caracteriza-se por ser algo dinâmico e inter-relacional, não sendo produto da natureza ou da biologia, mas sim de construções sociais localizados no tempo e na história. Tomando como ponto de referência tanto as vivências [em si] quanto às representações, sociais e midiáticas, o corpo ocupa um lugar central no modo como realizamos leituras sobre nós e os outros. Essas leituras, em geral dicotômicas, marcam e legitimam diferenças hierárquicas entre homens e mulheres. Ana Colling (2004, p. 16) afirma que "o corpo é o primeiro lugar de inscrição", nele,

a sociedade sempre leu, encarou a mulher a partir do corpo e de suas produções, fechando-a na reprodução do corpo e de suas produções. A natureza - menstruação, gravidez, parto, etc., - destinava as mulheres ao silêncio e a obscuridade, impossibilitando-as de outras formas de criação.

A Revolução Francesa trouxe consigo um momento pioneiro que ilustra o gene do pensamento feminista fundamental para a percepção da mulher como subalterna nas relações sociais, pensamento este que garantiria a muitas muIheres a luta por direitos igualitários. Segundo Márcia Rejane Messa (2008), um desses momentos ocorre quando, em 1759, a revolucionária Olympe de Gouges lança o manifesto intitulado "Declaração dos Direitos da Mulher", como resposta à "Declaração dos Direitos do Homem", um instrumento de cidadania restrito apenas ao sexo masculino. Além desse, foram muitos outros momentos históricos quando foi questionado o lugar e o papel que ocupam tanto o homem quanto a mulher na sociedade. A partir dessas e de outras formulações, ações e pensamentos, o gênero passou a ser compreendido, como aponta Verbena Laranjeira Pereira, "radicalmente como uma construção histórico/cultural, portanto, arbitrária, desvinculada do biológico" (PEREIRA, 2004, p.178).

Tanto homens quanto mulheres foram caracterizados por binarismos a partir da construção de discursos e conhecimentos sobre seus corpos e a atuação que neles se inscrevem. Nesses discursos, de modo geral, o feminino é caracterizado como,

natureza, emoção, amor, intuição, é destinado ao espaço privado; ao masculino - cultura, política, razão, justiça poder, o público. Essa di- 
cotomia constitui uma oposição desigual entre homens e mulheres, caracterizando a sujeição destas aos homens dentro de uma ordem aparentemente universal e igualitária (COLLING, 2004, p. 22).

Na sociedade atual, a mídia tem um importante papel na constituição de significado em torno das percepções dos papeis e identidades sociais e de gênero. Ela constrói lugares, prescreve normas e padrões culturais que fazem referência direta à organização social e às hierarquias vividas pelos sujeitos no cotidiano das práticas culturais. Para Tayana Dias de Menezes (2001) "observar a identidade social da mulher significa também observar como a mulher é vista pela sociedade" (MENEZES, 2001, p. 02). Mais do que apenas como é vista, faz-se necessário perceber como a imagem, que gera representações sociais, é construída pelos diferentes discursos sociais, em especial, o midiático, sendo diversamente utilizado pela publicidade com seus fins específicos.

É na contemporaneidade, para Josênia Antunes Vieira (2005), que noções ambivalentes e contraditórias sobre o sujeito coexistem, sujeito e objeto [mercadoria] se misturam. Vivemos em um mundo em que novos produtos são disponibilizados no mercado a todo o momento e no qual todos eles acabam, de alguma forma, concorrendo entre si, mesmo que não de forma direta.

Assim, é preciso tornar o produto conhecido cativando seu consumidor. Para alcançar o consumidor é preciso convencê-lo a entrar no seu jogo de comunicação, é preciso persuadi-lo. Para Peruzzolo (2008), a persuasão acontece quando alguém adota um valor pela importância que aquele valor tem para si. Ela está associada às convicções e crenças que o indivíduo carrega consigo, ou seja, não é possível persuadi-lo de algo que vá contra os seus princípios. Isso faz com que a atividade publicitária busque formas para envolver o consumidor, no intuito de provar sua veracidade e que aquele valor que está sendo transmitido é importante.

O maior objetivo de um publicitário é persuadir o consumidor a aceitar aquilo que é enunciado como um valor para si, como um valor do próprio consumidor. Por isso, o trabalho publicitário se esmera tanto na construção de sua mensagem buscando elementos que satisfaçam as necessidades, os desejos, os interesses e as expectativas do público a que se dirige, com a finalidade de que este público aceite, então, estreitar sua ligação com o produto.

Para Menezes (2001), às representações estão ligados significados simbólicos culturais, que servem tanto para classificar o mundo quanto para classi- 
ficar as relações entre os sujeitos. As representações, conforme nos mostra Liliany Samarão (2007), estão diretamente ligadas às culturas visuais urbanas, tornando-se a publicidade uma das principais atividades que se utiliza de imagens para a construção de significados.

Para chegar ao consumidor de forma mais rápida e eficaz, a publicidade muitas vezes utiliza-se de formas de representação como os estereótipos que já estão presentes e circulando na sociedade.

Conforme Lysardo-Dias (2007), a sociologia toma como estereótipo uma imagem mental coletiva que determina o pensar, agir e sentir do sujeito. Desta forma, por partilharem determinadas crenças e valores, os grupos sociais têm, através de seu próprio estereótipo, um modelo a ser seguido, e isso faz com que o indivíduo se sinta parte do grupo.

A publicidade brasileira direcionada para o público feminino, afirma Dylia Lysardo-Dias (2007), apresenta visivelmente dois tipos de estereótipos: (1) o estereótipo ligado ao padrão de beleza, sustentado pelo tripé mulher-bonita-magra; (2) e o de ser/parecer jovem como condição de para ser feliz. De acordo com a autora, o discurso publicitário "é um dos discursos que compõem a máquina midiática, também do ponto de vista ideológico" (LYSARDO-DIAS, 2007, p.30).

\section{OS NÚMEROS EM MARISA: SENTIDOS NÃO REVELADOS}

O anúncio publicitário audiovisual que analisamos é intitulado "Números" e tem como anunciante as Lojas Marisa. A função da peça, de 53 segundos de duração, é divulgar a coleção primavera-verão moda íntima 2012. Para isso, sua veiculação se deu na televisão aberta.

O comercial audiovisual inicia com uma tela na cor rosa-pink, sobre a qual recai um foco de luz no centro. Ali surgem dois bonecos: um representando homens e outro representando mulheres. O boneco representativo do homem passa a ser envolto por um círculo azul e o boneco representativo da mulher é envolvido por um círculo cor-de-rosa. Optamos por chamar as bolinhas cor-de-rosa de representação do feminino e as bolinhas azuis de representação do masculino.

Várias representações do masculino aparecem na tela formando o numeral 100. O mesmo processo ocorre com as representações do feminino que também se juntam, formando o numeral 96. É importante observarmos que os numerais formados são separados; polarizam-se, de um lado, os homens e, de outro, as mulheres. Assim, a partir das informações visuais e sonoras, tem-se 
que, no mundo, existem 100 homens para cada 96 mulheres.

No canto esquerdo superior da tela existe um relógio que contabiliza o número de homens para cada 96 mulheres. Desse número, são subtraídos os homens que se enquadram nas informações apresentadas pela locutora, informando o número de homens que ainda não foram excluídos da disputa. Também está presente uma modelo (bonita, magra, jovem), vestindo lingeries Marisa, que interage com a informação que está sendo apresentada.

A ideia central sobre a qual a redatora da peça se apoiou foi a de que, no jogo da sedução, de um total de 100 homens para 96 mulheres, 99 são descartáveis por apresentarem características que vão de encontro ao gosto das mulheres. Essas características são: não gostar do assunto, ou seja, são gays; apresentar traços de delicadeza ou cuidado consigo; morar com a mãe; possuir traços tidos como de homens mais rústicos ou bregas; não dar a mesma prioridade ou atenção ao sexo do que sua parceira; ser casado e ser casado e fiel.

Assim, o que alega o comercial, é que ao final desse processo de seleção resta um homem no mundo para cada 96 mulheres. Com a imagem focada na modelo, que desfila os preços de calcinhas e sutiãs, surge a informação sonora de que a telespectadora precisa caprichar para alcançar o único homem que sobrou. Possivelmente, isso ocorra através da escolha certa da lingerie.

À luz do circuito da cultura de Du Gay, alguns apontamentos podem ser feitos a respeito da instância da produção. Inicialmente, podemos perceber que a criação publicitária optou por considerar homens e mulheres como constituídos apenas de masculinidade e feminilidade. Através das representações do masculino e do feminino fica claro que entre homens não existe qualquer representação do feminino e entre mulheres não existe nenhuma representação do masculino. E mais, ao colocar homens de um lado e mulheres de outro, fica ainda mais evidente uma separação dos sexos.

Definitivamente, percebemos que a peça foi criada com o intuito de ser algo leve, engraçado, tematizando a difícil situação de encontrar um parceiro interessante neste mundo moderno. A publicidade desde sempre teve a característica de se apropriar de estereótipos que já circulam na sociedade para aproximar-se de forma mais rápida e eficaz do seu público-alvo. Mas, são os estereótipos escolhidos pela agência criadora adequados? Ou servem, neste caso, o uso de estereótipos?

Além disso, contemporaneamente, parece no mínimo inadequado abordar a narrativa de que na disputa pelo homem ideal o que dará sucesso à mulher 
será a lingerie. Primeiro, porque o homem ideal, como já diz tão bem a palavra, não é real. Sabemos que publicitários utilizam os estereótipos de príncipe encantado e de princesas para vender seus produtos, e é este o homem ideal Marisa-AlmapBBDO. Segundo porque, apesar de sabermos do fetiche que envolve as lingeries, o que não é novidade e de forma alguma um problema, ela se torna uma ferramenta de sedução. A lingerie, tal como a ideia do anúncio audiovisual, está mais uma vez associada ao estereótipo de felicidade. Com a lingerie certa, na narrativa, a mulher conquista o homem ideal e pode ser feliz.

Passamos agora para a análise na instância de representação. Os modos de representação estão diretamente ligados à construção identitária, também outra instância no circuito. As identidades são construídas através das representações quando a recepção as internaliza (identificando-se com elas) ou as refuta.

Logo no início da peça publicitária, encontramos uma série de elementos visuais e sonoros que, na narrativa apresentada, compõem formas distintas de representar homens (heterossexuais) e mulheres (também heterossexuais). A distinção entre os sexos se dá de forma clara, sempre colocando em oposição esses dois grupos. Qualquer forma que diverge do tipo de representação (ideal) dos sexos, tomada pela campanha, figura no sentido de exclusão.

A primeira representação a que somos apresentados pela campanha é a do homossexual masculino. De um determinado número de heterossexuais, diminuemse os indivíduos homossexuais que, segundo a peça publicitária, "não gostam do assunto". O homossexual, na narrativa, deixa de ser pensado como membro participante do gênero masculino. São considerados homens apenas os heterossexuais. Homossexuais são descartados, levando consigo, também, a bissexualidade, que não existe no binarismo homem/mulher (ideais), que figuram a história.

O anúncio aborda um grupo de representações que podemos classificar como destoantes das características socialmente construídas ao redor do perfil estereotipado da figura do macho. No somatório de homens a serem disputados pelas mulheres, subtraem-se aqueles que possuem um cachorro da raça poodle, tido como um cachorro de mulher, aqueles que têm medo de barata, os que secam o cabelo com secador e aqueles que fazem a unha. O perfil do homem ideal, procurado pelas mulheres do anúncio exclui um homem moderno, que se preocupa com a estética e os cuidados com sua higiene e aparência, reafirmando posições sociais nas quais apenas as mulheres, podem possuir um poodle e temer a baratas (sinais de fragilidade). Paradoxalmente, o homem desejado precisa ser delicado e cuidadoso para com a mulher, já que é indis- 
pensável que ele mande flores para a sua amada.

Se por um lado, o homem idealizado pela narrativa precisa ser desprovido de traços de delicadeza consigo mesmo, de cuidado com o corpo e com a aparência, traços esses que o excluem do seleto grupo dos machos, por outro lado, existem características, tidas como pertencentes a esse mesmo grupo que não são aceitáveis pelas mulheres. Palitar os dentes, usar cueca de vinco ou pochete fazem com que o homem seja desqualificado do processo seletivo. O homem ideal aqui, não pode apresentar características delicadas, nem rudeza.

O comercial apresenta, ainda, mais uma representação do homem desejado pela mulher-Marisa. Ele não pode morar com sua mãe, visto que isso denota uma posição de dependência materna, supondo que a sogra, no relacionamento, seria um incômodo. O homem ideal precisa ser emancipado, inclusive de sua família para que obtenha sucesso no relacionamento.

Na busca pelo macho ideal, a peça publicitária anuncia que é preciso subtrair os homens que pensam que, se falando em relação sexual, "as preliminares são coisas de mulher". A narrativa coloca que apenas as mulheres se preocupam com as demais formas do prazer sexual que não estão ligadas à penetração. Esses homens parecem não demonstrar que são carinhosos durante a relação sexual, já que apenas preocupam-se em chegar ao orgasmo de forma imediata.

Durante a narrativa somos apresentados a uma inusitada estatística, de que treze homens preferem declarar o imposto de renda a fazer sexo. Essa afirmação generaliza um determinado comportamento do homem para o qual pode existir um número de variáveis que não figuram na história. Se existem homens que realmente têm essa preferência, devem existir explicações para tal, sejam problemas nos relacionamentos afetivos, desinteresse na relação sexual, preocupação com o trabalho, sintomas de um comportamento workaholic, ou ainda, simplesmente, o fato do homem estar ocupado no momento em que sua parceira deseja sexo, implicando que ele deva estar permanentemente à sua disposição.

Duas últimas representações figuram no enredo da peça publicitária, a de que dezessete dos homens restantes são casados, o que elimina qualquer possibilidade de uma mulher apaixonar-se ou envolver-se com um homem casado, excluem-se os relacionamentos extraconjugais, as amantes, os relacionamentos abertos ou as práticas do poliamor. Além dos dezessete homens anunciados como casados, mais um é apresentado como sendo casado e fiel à sua 
mulher. Sobra apenas um único homem para ser disputado entre 96 mulheres.

A campanha termina com a ideia de que, na disputa pelo homem ideal, à mulher não cabe outra alternativa além de "caprichar". Por capricho, entendese que ela precisa ser magra, bonita e sensual, tal como a modelo da peça. Mas isso apenas não basta, a lingerie se torna um acessório de sedução da mulher. A mulher precisa vestir a lingerie ideal, para tornar-se uma mulher ideal, com mais chances de conquistar um homem ideal. Dessa forma, a estatística apresentada se inverte, passando a contabilizar o número de mulheres ideais (as que vestem a lingerie Marisa) e as não-ideais, que precisam contentar-se com os homens descartados durante o processo de disputa. O homem ideal não lhe cabe.

A representação da mulher como objeto é o cerne do comercial e demonstra o que Acevedo (2003, p. 2) afirma serem os três papeis frequentemente destinados às mulheres na publicidade: "como objeto sexual, como beleza física e como dependente do homem". Nesse comercial é possível identificar esses três papeis.

Além desses três papeis, há quatro estereótipos que ainda são predominantes quando se trata do papel das mulheres na publicidade: 1) o lugar da muIher é em casa; 2) as mulheres não devem tomar importantes decisões ou fazer coisas importantes; 3) as mulheres são dependentes e necessitam da proteção dos homens e; 4) os homens veem a mulher como objeto sexual e não ser humano (COURTNEY e LOCKERETZ, 1971 apud ACEVEDO, 2003, p. 2).

No que concerne à instância do consumo da peça publicitária, devemos ressaltar que fazemos referência não à recepção da narrativa televisionada, mas sim, tendo como suporte a internet, já que o vídeo da campanha foi postado em alguns sites, através dos quais, fazendo uso das ferramentas de interatividade, o público pode opinar. As falas que destacamos são, portanto, uma amostra do consumo da narrativa, dado aos posicionamentos dos consumidores que a regulam. É aqui que encontramos a construção do significado na recepção. Em nossa análise, aliamos o consumo à regulação por parte daqueles que assistiram ao comercial e se posicionaram. Portanto, não existe regulação (por parte de quem vê) sem antes ter ocorrido o consumo, estando essas duas instâncias, bem como as demais, extremamente ligadas.

Qualquer produto cultural está sujeito à regulação, outra instância do circuito. No caso do comercial das Lojas Marisa, a regulação acontece a partir das leituras dos próprios receptores. Apesar de ainda vivermos em uma sociedade bastante machista, a situação vem mudando lentamente. A internet tornou-se 
um meio para que as pessoas exponham suas opiniões, demonstrem suas ideias e debatam sobre o machismo que existe em vários os âmbitos da sociedade.

Foi na internet que o comercial virou notícia em blogs, o que torna a regulação, nesse caso, como a parte mais importante deste produto cultural. Houve uma grande manifestação nas redes sociais e em blogs. Alguns consideraram a propaganda criativa e bem humorada, não levantando outros questionamentos, por outro lado, outros entenderam a propaganda como "machista, retrógrada, [e] sexista". Muitos comentários inclusive, foram feitos na própria fanpage da agência AlmapBBDO no Facebook'. Alguns, como:

Retratação pelo comercial da Marisa já! - Respeito é bom, e nós, consumidoras, gostamos! Seria um gesto de humildade e inteligência (pois desconfio que a demora em desculpar-se está em ainda não compreenderem o teor de nossas reclamações).

“aqui a gente pensa antes de fazer"...hahahahahahahahahaha Nem antes, nem depois. Custa muito reconhecer o erro e se retratar?".

Sabe onde a propaganda da Marisa vais estar? Na página de denúncias daqui ó: http://www.conar.org.br/home.html.

"Propagandas machistas, sexistas, heteronormativas e que, claro, só mostram mulheres BRANQUINHAS e MAGRINHAS. Lixo”.

Essas são apenas algumas das reclamações retiradas dos comentários da página do Facebook, escolhidas de forma a compor exemplos emblemáticos do que estamos chamando de regulação feita pelos próprios receptores. Vale ressaltar que a agência e a marca não responderam nenhuma das reclamações. Como o movimento contra a agência e a campanha foi grande, a redatora da agência de publicidade, AlmapBBDO, criadora do comercial, resolveu se manifestar sobre a propaganda. Selecionamos um fragmento do texto da redatora, através do qual pode-se perceber alguns critérios adotados pela instância da produção da campanha:

Sim, a pessoa que vê machismo em tudo é aquela que de fato é. Assim como a pessoa que vê preconceito em tudo é a mais preconceituosa de todas. Só quem acha que negro é algo negativo se ofende

1 Fanpage AlmapBBDO no Facebook. Disponível em: <https://www.facebook.com/AlmapBBDO?fref=ts>. Acesso em: out. 2012. 
com essa palavra e pensa que falar afro-qualquer-coisa diminui a carga de preconceito que carrega consigo mesma. Pois bem, o comercial de Marisa foi criado por uma mulher. Que trabalha de sol a sol ao lado "desses caras". E que acredita piamente na força da mulher. Mas que, ingenuamente, acreditou que as mulheres tinham evoluído o suficiente para rirem de si mesmas. Mas, não. O humor é uma conquista maior. As mulheres podem ter conquistado independência financeira, mas não se livraram de seu complexo de inferioridade. $O$ comercial brinca com a dificuldade de se encontrar um homem. Não, não me venham dizer que é fácil. (E antes que falem "e as lésbicas?", estou falando da maioria, que ainda é hetero.) O comercial cria uma estatística fictícia usando tipos de homens que não se encaixam exatamente no modelo de príncipe encantado. O que me alivia é o fato do comercial também ter sido elogiado. Por homens e mulheres. Porque, esteja você ou não à procura do par ideal, aprenda: o humor é extremamente sedutor e sexy. E não essa ranhetice vigente que nos invade por todos os lados. Uma boa gargalhada ainda é um dos mais poderosos afrodisíacos. [...] P.S.: Este texto foi cuspido em dez minutos, com o mero intuito de meu fígado não ser atingido pela minha raiva momentânea. [...] É isso. Não levem a sério, tá? Já tem muita gente fazendo isso (SCHOENBURG, material online). ${ }^{2}$

Nota-se uma rispidez no texto da autora, não se desculpando em nenhum momento com as pessoas que se sentiram ofendidas pelo comercial. Por isso, em vez de atenuar a imagem negativa da marca e da agência de publicidade, o texto gerou mais repercussão negativa. Uma das principais críticas feitas ao texto da redatora, foi a de um blog de feministas, "Slut Shaming Detected3", que copiou o texto, enumerou seus principais argumentos e os rebateu. Destacamos alguns desses argumentos:

E quem disse que só porque é mulher não pode ser machista, minha filha? Algumas das pessoas mais machistas que eu conheço são do gênero feminino. Não pense que, por sofrer pressão do patriarcado, você está imune ao machismo. Muito pelo contrário. [...] Uai, mas "agarrar macho" é justamente a mensagem central da SUA campanha, mulher! Seja coerente, pelo menos! [...] Se vemos machismo em tudo, é porque ele de fato existe. Quem o tenta negar é que é machis-

2 O Espaço é Seu - Por onde anda o bom humor? (Sophie Schoenburg). Disponível em <http:// ccsp.com.br/ultimas/60102/O-Espaco-e-Seu> Acesso em: nov. 2012.

3 SlutShamingDetected. Disponível em <http://slutshamingdetected.tumblr.com/ post/30120992688> Acesso em: nov. 2012. 
ta. É como o branquinho classe média que nega o racismo. [...] mais uma que pensa que uma camisa escrito " $100 \%$ caucasiano" é igual a uma escrito "100\% negro" [...] Dificuldade? Meu deus, eles são metade da população! Ah é, o seu não pode usar secador, fazer unhas, ter um poodle, porque isso não é coisa de "homem de verdade" [...] Homofobia. Porque lésbica não compra lingerie [...] Cê e sua audiência já não estão um pouco grandinhos pra esse negócio de príncipe encantado? [...]E termina chamando a gente de mal comida. Parabéns, hein, fia. [...] Análise do discurso mandou um beijo pra você, tá?

Apesar de toda essa repercussão, a agência não se manifestou sobre a campanha - a única interação com o público por parte da agência foi o texto da redatora. As Lojas Marisa apenas disseram em uma nota que "não houve intenção de desmerecer os homens ou incentivar o machismo e sim de se aproximar do universo das mulheres, considerando as dificuldades que muitas têm com o 'clichê' de encontra o homem ideal”. Também em nota, o CONAR (Conselho Nacional de Autorregulamentação Publicitária), afirmou que não vetou a propaganda, apesar de ter recebido cerca de 50 reclamações por parte do público, pois entendeu que a campanha se baseava no humor e não continha ofensa a nenhum grupo. ${ }^{4}$

Mesmo com essa decisão das autoridades e das empresas, a repercussão negativa continua nas redes sociais e chega a ir para o ambiente offline. Há grupos que combinaram "marchas" contra a empresa e sua propaganda, assinaram petições contra a loja e, ainda, alguns que fizeram campanha para boicotar a empresa.\{Há algum dado que exemplifique essas marchas, petições, etc? Seria interessante citar algum.\}

\section{CONSIDERAÇÕES FINAIS}

O circuito da cultura, proposto por Du Gay, nos dá uma dimensão inter-relacionada entre as diferentes instâncias de circulação de um produto cultural. O esforço que realizamos com essa análise foi o de percebermos o que está localizado em cada uma das instâncias que compreendem o circuito, produção, representação, consumo, identidade e re-

4 Conar arquiva processo contra comercial de lingerie da Marisa. Disponível em <http://economia.terra.com.br/noticias/noticia.aspx?idNoticia=201210021352_TRR_81631121>. Acesso em: nov. 2012. 
gulação - bem como a relação entre si das instâncias - da peça publicitária Números, referente ao anúncio de venda de lingeries das Lojas Marisa. Nenhuma instância do circuito da cultura mostra-se independente da outra. $\mathrm{O}$ significado de algum produto cultural transita por todas elas e não se deposita em completude, finitude e peso, em nenhuma forma de isolamento. Através da análise percebemos que nenhum discurso - e entre eles, o publicitário - nasce sem uma intenção ou é livre de interpretações diferentes, às vezes opostas ou contraditórias. É analisando a instância da produção, de um determinado produto cultural, que podemos perceber algumas marcas e representações presentes naquilo que está sendo anunciado. Essas representações estão diretamente ligadas ao modo como são construídas as representações sobre o outro - e sobre o mundo - que incidem sobre a construção das identidades construída por parte dos receptores, que pensam sobre essas identidades, mas que também as regulam.

No caso da campanha publicitária Números, percebemos que a regulação ocorreu por parte dos consumidores do anúncio que, não satisfeitos com o tipo de representação de gênero, proposto pela narrativa, recorreram às ferramentas da internet para debaterem, comentarem e exporem suas opiniões. Vale ressaltarmos a intensidade da regulação, por parte dos consumidores, para com o produto. Muitas vozes e pontos de vista foram levantados, indignações tornaram-se conhecidas e foram compartilhadas. A produção percebe, então, que os consumidores, ou ao menos alguns deles, mostramse atentos aos acontecimentos que os cercam, às veiculações midiáticas que, de alguma forma, Ihes dizem respeito. As anunciantes não estão sozinhos, produzidos para um público inerte. Os consumidores são capazes de levantarem debates e reflexões sobre aquilo que Ihes é direcionado. Destacamos também as possibilidades do uso da internet - através das ferramentas de interatividade - que nos possibilitaram conhecer um pouco das leituras (e do embate) realizados pelo público e, além disso, através da internet, formas de regulação da produção se tornaram possíveis. Os sujeitos puderam opinar, manifestando-se sobre a campanha, demonstrando sua aceitação ou repúdio. A análise nos deixa a refletir: Qual a intensidade dessa regulação? Até onde, de fato, opera? O que desloca? Questionamentos estes possíveis graças à tentativa de percepção da circulação da cultura, nesta análise, da campanha publicitária Números, de forma cíclica e não estagnada - dentro do qual os sujeitos operam e de onde retiram os significados que passam a lhes pertencer. 


\section{REFERÊNCIAS}

ACEVEDO, Claudia R. Mulheres em propaganda: um estudo da percepção feminina. 2003. Trabalho apresentado no XXIII Encontro Nacional de Engenharia de Produção, Ouro Preto, 2003. Disponível em <http://www.abepro.org.br/biblioteca/ENEGEP2003_TR0707_0445. pdf>. Acesso em: nov. 2012.

AlmapBBDO. Fanpage, Facebook. Disponível em: <https://www.facebook.com/AlmapBBDO?fref=ts>. Acesso em: out. 2012.

ALMEIDA, Sandra Regina Goulart. Gênero, Identidade, Diferença. In: Aletria. UFMG, v. 9, n. 1, p. 90-97, 2002.

COLLING, Ana. A construção histórica do feminino e do masculino. In: STREY, Marlene Neves; CABEDA, Sonia T. Lisboa; PREHN, Denise Rodrigues (orgs.).Gênero e cultura: questões Contemporâneas. EDIPUCRS, Porto Alegre, p. 13-38, 2004.

DU GAY; HALL, et al. Doing cultural studies: The story of the Sony Walkman. Glasglow: The Open University, 1997.

ESCOSTEGUY, Ana Carolina. Os estudos culturais. Cartografias. Porto Alegre: PUCRS, 2001. Disponível em <http://www.pucrs.br/famecos/pos/cartografias/estudos_culturais_08_06. php\#referencia> Acesso em: out. 2012.

- Quando a recepção já não alcança: os sentidos circulam en-

tre a produção e a recepção. E-Compós, Brasília, v. 12, n. 1, p. 1-15, jan./abr., 2009. Disponível em <http://www.compos.org.br/seer/index.php/e-compos/article/viewFile/348/318> Acesso em: nov. 2012.

LYSARDO-DIAS, Dylia. A construção e a desconstrução de estereótipos pela publicidade brasileira. Disponível em <http://www.lai.su.se/gallery/bilagor/SRoLAS>. Acesso em: nov. 2012.

MENEZES, Tayana Dias de. As mídias e a representação feminina: Um estudo sobre a identidade social da mulher. Dissertação de Mestrado, Programa de Pós-Graduação em Letras, Centro de Artes e Comunicação, Universidade Federal de Pernambuco, Recife, 2001.

MESSA, Márcia Rejane. Os estudos feministas de mídia: uma trajetória anglo-americana. In: ESCOSTEGUY, Ana Carolina D. (org.). Comunicação e gênero: A aventura da pesquisa. EDIPUCRS, Porto Alegre, p. 38-60, 2008.

PEREIRA, Verbena Laranjeira. Gênero: Dilemas de um Conceito. In: STREY, Marlene Neves; CABEDA, Sonia T. Lisboa; PREHN, Denise Rodrigues (orgs.).Gênero e cultura: questões Contemporâneas. EDIPUCRS, Porto Alegre, p. 13-38, 2004.

PERUZZOLO, Adair C.Fazer Crer, Fazer Valer. In: CASTRO, L. D. (Org.). Em torno das mídias, práticas e ambiências. 01 ed. Porto Alegre, RS: Sulina, v. 01, p. 151-177, 2008.

PIEDRAS, Elisa; JACKS, Nilda. A publicidade e o mundo social: uma articulação pela ótica dos Estudos Culturais. Contemporânea, v. 3, n. 2, p. 197-216, jul./dez., 2005. Disponível em <http://www.sumarios.org/sites/default/files/pdfs/piedras_o.pdf>. Acesso em: nov. 2012. 
SAMARÃO, Liliany. O espetáculo da publicidade: a representação do corpo feminino na mídia. Contemporânea, v. 8, n.1, p. 45-57, 2007.

SCHOENBURG, Sophie. Por onde anda o bom humor? In: Últimas. O espaço é seu. Disponível em <http://ccsp.com.br/ultimas/60102/O-Espaco-e-Seu> Acesso em: nov. 2012.

SLUT SHAMING DETECTED. Resposta a Sophie Schoenburg. Disponível em <http://slutshamingdetected.tumblr.com/post/30120992688> Acesso em: nov. 2012.

TERRA, Portal de Notícias. Conar arquiva processo contra comercial de lingerie da Marisa. Notícia de 02 de outubro de 2012. Disponível em <http://economia.terra.com.br/noticias/noticia.aspx?idNoticia=201210021352_TRR_81631121>. Acesso em: nov. 2012.

VIEIRA, Josênia Antunes. A identidade da mulher na modernidade. D.E.L.T.A 21: Especial, p. 207-238, 2005.

WILLIAMS, Raymond. Palavras-chave: um vocabulário de cultura e sociedade. Tradução de Sandra Guardini Vasconcellos. São Paulo: Boitempo, 2007.

RECEBIDO EM: 06/11/12

ACEITO PARA PUBLICAÇÃO: 25/11/12 


\section{Alisson Machado}

Possui graduação em Comunicação Social, habilitação em Jornalismo, pela Universidade Federal de Santa Maria (2011). Atualmente, é aluno de graduação do curso de Ciências Sociais e do Programa de Pós-Graduação em Comunicação, em nível de mestrado, pela mesma instituição. Interessado na investigação sobre cinema-documentário, representações sociais, culturas e identidades.

\section{Carline Ternus}

Possui graduação em Comunicação Social, habilitação em Publicidade e Propaganda, pela Universidade Federal de Santa Maria (2011). Atualmente, é aluna de graduação do curso de Ciências Sociais e do Programa de Pós-Graduação em Comunicação, em nível de mestrado, pela mesma instituição. Interessada na investigação sobre identidades, televisão e semiótica discursiva

\section{Gabriela S. Santos}

Possui graduação em Comunicação Social, habilitação em Publicidade e Propaganda pelo Centro Universitário Franciscano (2011). Atualmente é aluna do Programa de Pós-Graduação em Comunicação, em nível de mestrado, pela Universidade Federal de Santa Maria (UFSM). Interessada em estudos de gênero, etnografia virtual e telenovela. 